\title{
Effect of Annealing Temperature on Optoelectronic Performance of F- and Al-codoped ZnO Thin Films for Photosensor Applications
}

\author{
Chi-Fan Liu, Tao-Hsing Chen, ${ }^{*}$ and Jia-Ting Huang \\ Department of Mechanical Engineering, National Kaohsiung University of Science and Technology, \\ No. 415, Jiangong Rd., Sanmin Dist., Kaohsiung City 80778, Taiwan
}

(Received June 28, 2020; accepted October 20, 2020)

Keywords: FAZO thin film, optical property, electrical property, annealing temperature

Fluorine- and aluminum-codoped $\mathrm{ZnO}$ (FAZO) thin films are sputtered on Corning glass substrates using an RF magnetron sputtering system. The structural, electrical, and optical properties of the deposited thin films are investigated under the as-sputtered condition and after annealing at temperatures of $200-400{ }^{\circ} \mathrm{C}$. X-ray diffraction (XRD) analysis results show that a higher annealing temperature is beneficial in improving the crystallinity of the FAZO films. An annealing temperature of $400{ }^{\circ} \mathrm{C}$ results in the lowest electrical resistivity $\left(4.1 \times 10^{-4} \Omega \cdot \mathrm{cm}\right)$ and highest average transmittance (78.43\%) among the deposited films. Moreover, an annealing temperature of $400{ }^{\circ} \mathrm{C}$ increases the energy bandgap from $3.06 \mathrm{eV}$ under the as-sputtered condition to $3.21 \mathrm{eV}$ after annealing and promotes a strong grain growth effect. As a result, the annealed FAZO film is an ideal material for solar cells and photosensor applications.

\section{Introduction}

Transparent conductive oxide (TCO) films have many favorable properties, including high transmittance at visible wavelengths, high electrical conductivity, low resistivity, and high carrier density. ${ }^{(1-3)}$ As a result, they are widely used in many different applications nowadays, including photosensors or gas sensors, thin-film solar cells, liquid crystal display monitors, and light-emitting diodes (LEDs). ${ }^{(4-9)}$ Among the various materials available for the fabrication of TCO films, indium oxide $\left(\mathrm{In}_{2} \mathrm{O}_{3}\right)$, tin oxide $\left(\mathrm{SnO}_{2}\right)$, and zinc oxide $(\mathrm{ZnO})$ are among the most commonly used. $\mathrm{In}_{2} \mathrm{O}_{3}$ and $\mathrm{SnO}_{2}$ are n-type semiconductors. However, $\mathrm{ZnO}$ may be either an $\mathrm{n}$-type semiconductor or a p-type semiconductor, depending on the dopants used. ${ }^{(10,11)} \mathrm{ZnO}$ is characterized by nontoxicity and natural abundance and is therefore regarded as a particularly attractive candidate material for the fabrication of TCO thin films. ${ }^{(12-14)}$ Owing to their desirable physical properties, e.g., high transmittance and high conductivity, ZnO-based thin films have many applications in the electrical and energy industries. Furthermore, as an n-type semiconductor, $\mathrm{ZnO}$ has a high direct energy bandgap of $3.37 \mathrm{eV}$ at room temperature and is thus well suited to the development of optical and electrical elements. 
Many studies have shown that the electrical, optical, chemical, and physical properties of TCO thin films can be effectively controlled by adjusting their deposition parameters. ${ }^{(15,16)}$ Moreover, the properties can also be tuned through the addition of carefully chosen dopants during the deposition process. For example, the addition of group III elements such as B, $\mathrm{Al}, \mathrm{Ga}$, and In to ZnO-based TCOs improves both the conductivity of the thin film and the optoelectronic performance. ${ }^{(17-19)}$ To achieve good transmittance in the visible light range, the energy bandgap of TCO thin films must be greater than the energy of visible light (i.e., $3.0 \mathrm{eV}$ ). The literature contains extensive studies on the properties of doped TCO thin films, including indium tin oxide (ITO), ${ }^{(20,21)}$ fluorine-doped tin oxide (FTO), ${ }^{(22,23)}$ aluminum-doped zinc oxide (AZO), ${ }^{(24,25)}$ titanium-codoped $\mathrm{ZnO},{ }^{(26)}$ and gallium-doped zinc oxide (GZO). ${ }^{(27,28)}$ In general, these studies have all shown that such films have excellent potential for specific applications, such as solar cells, organic LEDs (OLEDs), and photosensors.

Anion dopants such as fluorine $(\mathrm{F})$ and chlorine $(\mathrm{Cl})$ are particularly attractive for $\mathrm{ZnO}$ films since they readily substitute for the oxygen atoms in the $\mathrm{ZnO}$ lattice and provide an extra conducting electron as a result. Moreover, the ionic radius of fluorine is very close to that of oxygen (F: $1.31 \AA$, O: $1.38 \AA$ ), resulting in minimal lattice distortion. ${ }^{(29)}$ Furthermore, Al may enhance the electrical properties of $\mathrm{ZnO}$. However, the literature contains scant information on the effects of the annealing temperature on the optoelectronic properties of $\mathrm{ZnO}$ thin films with doped elements. ${ }^{(30)}$ Accordingly, in the present study, fluorine- and aluminum-codoped $\mathrm{ZnO}$ (FAZO) thin films are deposited on glass substrates using an RF magnetron sputtering system and then annealed at temperatures ranging from 200 to $400{ }^{\circ} \mathrm{C}$. The structural, electrical, optical, and surface properties of the films are then investigated in order to determine which film provides the highest optoelectronic performance. ${ }^{(31)}$

\section{Experimental Procedure and Material Preparation}

Glass substrates were purchased from Corning Company and cut into test pieces with a size of $2 \times 2 \mathrm{~cm}^{2}$. The test pieces were cleaned by sonication in acetone and ethanol for $10 \mathrm{~min}$ each and then washed in deionized water, blow-dried in a high-pressure nitrogen gas flow, and placed in an oven at $80{ }^{\circ} \mathrm{C}$ for $1 \mathrm{~h}$ to remove any remaining moisture content. FAZO films were then deposited on the glass substrates using a commercial RF magnetron sputtering system (Ishi Vacuum, I Shien Co., Ltd.). The FAZO targets used in the sputtering process consisted of 97 at.\% $\mathrm{ZnO}(99.999 \%), 2.0 \mathrm{wt} \%$ aluminum oxide $\left(\mathrm{Al}_{2} \mathrm{O}_{3}\right)(99.999 \%)$, and $2 \mathrm{wt} \%$ zinc fluoride $\left(\mathrm{ZnF}_{2}\right)(99.995 \%)$. The powder mixture was pressed in a cold isostatic press and then sintered at a high temperature to form a ceramic target with a diameter of $2 \mathrm{in}$. and a thickness of $6 \mathrm{~mm}$. Prior to sputtering, the vacuum chamber was evacuated to a base pressure of less than $1.5 \times 10^{-4} \mathrm{~Pa}$. FAZO films were then deposited on the glass substrates using a target-to-substrate distance of $15 \mathrm{~cm}$, a target power of $50 \mathrm{~W}$, a bias pressure of 6 mTorr, an argon gas flow rate of $15 \mathrm{sccm}$, and a sputtering time of $90 \mathrm{~min}$. Following the sputtering process, half of the specimens were retained under the as-deposited condition, while the remainder were annealed at temperatures of $200-400{ }^{\circ} \mathrm{C}$ for $10 \mathrm{~min}$. 
The structural characteristics of the FAZO films were investigated by X-ray diffraction (XRD, SIEMENS D5000). In addition, the electrical resistivity of the films was measured using a Hall instrument (Advanced Design Technology Company), while transmittance spectra were obtained using a UV-Vis spectrophotometer (Hitachi U-4001). Surface morphologies were examined by scanning electron microscopy (SEM, Philips XL-40 FEG) and atomic force microscopy (AFM, Digital Instruments D5000). Finally, photoluminescence (PL) spectra were obtained using a PL spectroscope (JASCO FP-6200).

\section{Results and Discussion}

\subsection{XRD crystal structural analysis}

The FAZO film thickness was measured to be around $140 \mathrm{~nm}$ using an alpha step profilometer. The film thickness was unaffected by heat treatment and showed no change as the annealing temperature was increased. As shown in Fig. 1, all of the films (both asdeposited and annealed) exhibit strong growth in the (002) direction together with minor secondary growth in the (103) direction. In other words, film growth occurs along the c-axis in a direction normal to the substrate surface. Note that this growth behavior is consistent with that reported in previous studies on $\mathrm{ZnO}$ thin films. ${ }^{(11,15)}$ Hence, it is inferred that the $\mathrm{F}$ and $\mathrm{Al}$ dopants added to the $\mathrm{ZnO}$ film have no effect on the crystal growth direction. It is further seen that the intensity of the (002) peak increases with the annealing temperature. This implies that a higher annealing temperature is beneficial in improving the crystallinity of the FAZO structure. Moreover, XRD patterns show no evidence of $\mathrm{Al}$ or $\mathrm{F}$ structures, which indicates that the dopants are either substituted in the $\mathrm{Zn}$ or O sites of the original $\mathrm{ZnO}$ crystal structure or segregated in the noncrystalline regions of the FAZO film structure at grain boundaries.

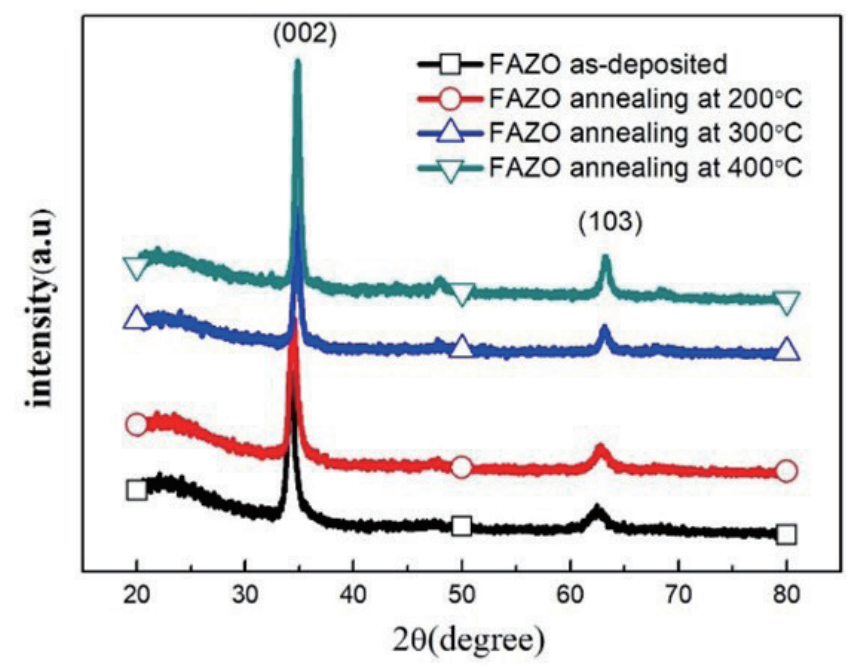

Fig. 1. (Color online) XRD patterns of FAZO films annealed at different temperatures. 


\subsection{Electrical properties of FAZO films}

Figure 2 shows the electrical properties of the FAZO films processed at different annealing temperatures. The results show that the resistivity decreases from $1.75 \times 10^{-3}$ to $4.1 \times 10^{-4} \Omega \cdot \mathrm{cm}$ as the annealing temperature increases to $400{ }^{\circ} \mathrm{C}$. To verify that the highest electron mobility is obtained at the annealing temperature of $400{ }^{\circ} \mathrm{C}$, we attempted annealing at $500{ }^{\circ} \mathrm{C}$. It can be observed in Fig. 2 that the resistivity increased significantly to $3.7 \times 10^{1} \Omega \cdot \mathrm{cm}$. As a result, we concluded that the best electrical property was obtained at the annealing temperature of $400{ }^{\circ} \mathrm{C}$. By contrast, the carrier concentration increases markedly from $7.6 \times 10^{19} \mathrm{~cm}^{-3}$ in the as-deposited specimen to $3.69 \times 10^{20} \mathrm{~cm}^{-3}$ following annealing at $400{ }^{\circ} \mathrm{C}$. The mobility also increases with the annealing temperature, rising to a maximum of $65 \mathrm{~cm}^{2} / \mathrm{Vs}$ in the specimen annealed at $400{ }^{\circ} \mathrm{C}$. Table 1 shows the electrical properties of all the FAZO films. In general, the improved electrical properties of the FAZO films with increasing annealing temperature can be attributed to the greater crystallinity of the FAZO structure at higher annealing temperatures, which enhances the carrier trapping effect at grain boundaries and reduces the number of internal defects.

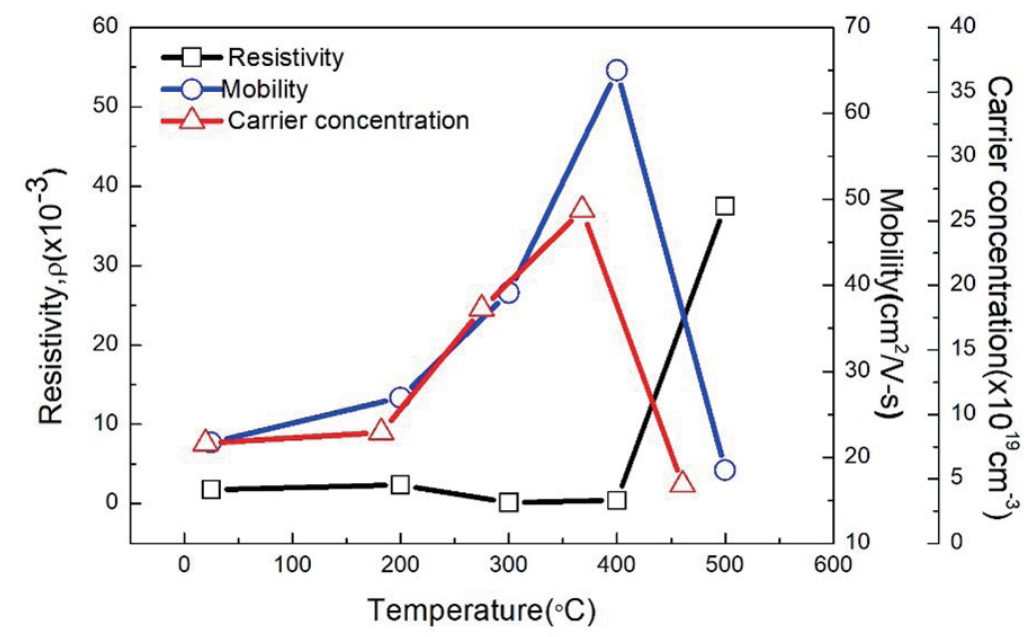

Fig. 2. (Color online) Electrical properties of FAZO films annealed at different temperatures.

Table 1

Electrical properties of FAZO films annealed at different temperatures.

\begin{tabular}{lccc}
\hline & \multicolumn{4}{c}{ FAZO 50 W 6 mTorr 15 sccm } \\
\hline $\begin{array}{l}\text { Annealing temperature } \\
\left({ }^{\circ} \mathrm{C}\right)\end{array}$ & $\begin{array}{c}\text { Resistivity } \\
(\Omega \cdot \mathrm{cm})\end{array}$ & $\begin{array}{c}\text { Mobility } \\
\left(\mathrm{cm}^{2} / \mathrm{Vs}\right)\end{array}$ & $\begin{array}{c}\text { Carrier concentration } \\
\left(\mathrm{cm}^{-3}\right)\end{array}$ \\
\hline As-deposited & $1.75 \times 10^{-3}$ & 21.73 & $7.61 \times 10^{19}$ \\
\hline 200 & $2.36 \times 10^{-3}$ & 26.94 & $8.98 \times 10^{19}$ \\
\hline 300 & $1.7 \times 10^{-4}$ & 39.13 & $2.45 \times 10^{20}$ \\
\hline 400 & $4.1 \times 10^{-4}$ & 65.0 & $3.69 \times 10^{20}$ \\
\hline
\end{tabular}




\subsection{Transmittance and optical properties of FAZO films}

Figure 3 shows the transmittance spectra of the FAZO films processed at different annealing temperatures for incident wavelengths ranging from 300 to $800 \mathrm{~nm}$. All of the films have a strong absorption edge in the transmittance spectrum in the UV region $(\sim 350 \mathrm{~nm})$. In addition, the transmittance of the FAZO films increases with the annealing temperature and attains a maximum of approximately $80 \%$ at $400{ }^{\circ} \mathrm{C}$. In other words, the annealing process significantly improves the optical properties of the FAZO films. One of the most important optical properties of TCO thin films is the energy bandgap $\left(E_{g}\right)$, i.e., the energy required for a valence electron bound to an atom to break free from the atom and become a conduction electron. A higher $E_{g}$ indicates a higher transmittance, and according to the literature, the value for a TCO thin film is about 3.1-3.2 eV. To obtain $E_{g}$, the optical absorption coefficient $(\alpha)$ of the film is first estimated as

$$
\alpha=(-\ln T) / d
$$

where $T$ is the optical transmittance (see Fig. 3) and $d$ is the thickness of the film. $E_{g}$ can then be determined using the Tauc formula, which applies a linear extrapolation method to the linear region of the plot of the optical absorption coefficient $(\alpha)$ versus the photon energy $(h v),{ }^{(32-37)}$ i.e.,

$$
\alpha h v=A\left(h v-E_{g}\right)^{1 / 2},
$$

where $A$ is the constant for a direct transition, $h$ is Planck's constant, and $v$ is the frequency of the incident photon. Figure 4 shows the calculated energy bandgaps of the present films prepared at various annealing temperatures. The energy bandgap increases from $3.06 \mathrm{eV}$ for the as-sputtered condition to $3.21 \mathrm{eV}$ after annealing at $400{ }^{\circ} \mathrm{C}$. In other words, the energy bandgap

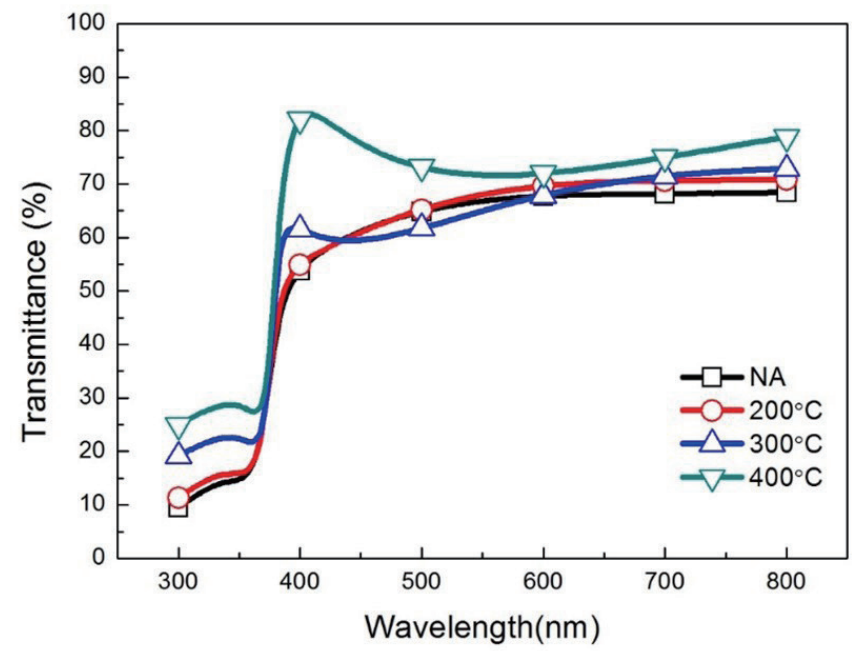

Fig. 3. (Color online) Transmittance spectra of FAZO films annealed at different temperatures. 


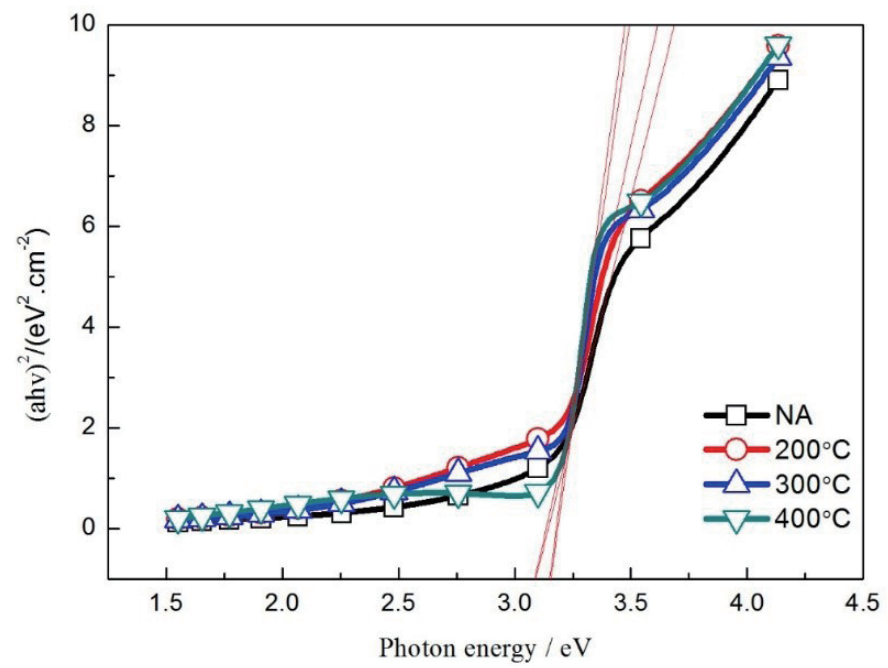

Fig. 4. (Color online) Variation in $(\alpha h v)^{2}$ with photon energy for FAZO films annealed at different temperatures.

of the FAZO films increases with the annealing temperature. From the Burstein-Moss theory, it is inferred that the carrier density increases with the annealing temperature, which increases the energy bandgap accordingly. ${ }^{(38,39)}$

\subsection{Surface analysis of FAZO films}

Figures 5(a)-5(d) show SEM surface images of the FAZO thin films processed at different annealing temperatures. The as-deposited film contains a few pinholes and has a rough surface [Fig. 5(a)]. Consequently, the motion of the carriers on the film surface is impeded and the carrier mobility is low (see Fig. 2). However, as the annealing temperature increases, the grain size also increases and the morphology becomes smoother and denser. As a result, the motion of the carriers is enhanced and the carrier mobility increases.

\subsection{FAZO film grain size analysis}

The full widths at half maximum (FWHMs) of the FAZO films were obtained from the (002) peaks shown in Fig. 1 and were used to calculate the grain size in accordance with the Scherrer formula given in Eq. (3) (note that $D$ is the grain size, $\lambda$ is the wavelength of the incident light, and $\beta$ is the FWHM). As shown in Fig. 6, the average grain size increases significantly from $31 \mathrm{~nm}$ for the as-deposited film to $81 \mathrm{~nm}$ for the film annealed at $400{ }^{\circ} \mathrm{C}$. In other words, the finding from Fig. 2 that the crystallinity of the FAZO film improves with increasing annealing temperature is confirmed.

$$
D=\frac{0.9 \lambda}{\beta \cos \theta}
$$




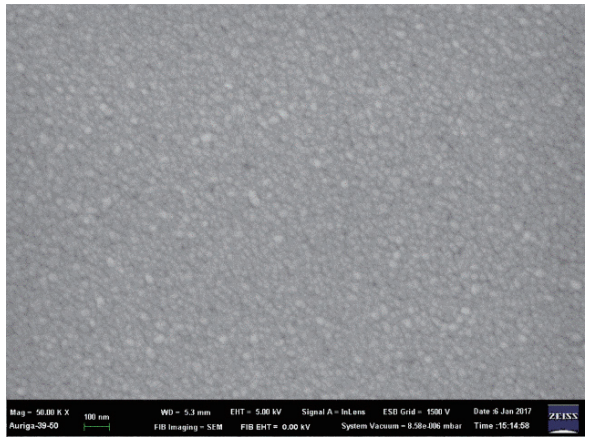

(a)

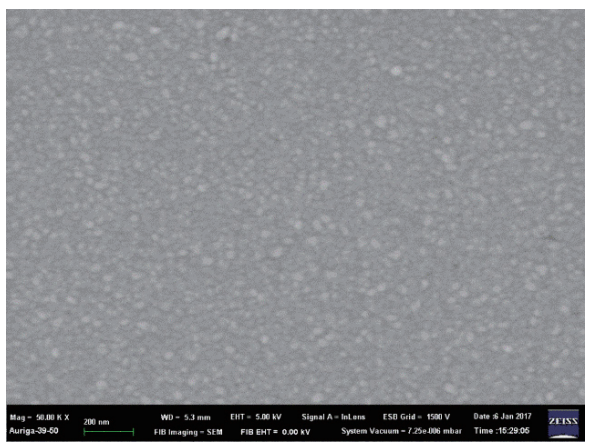

(c)

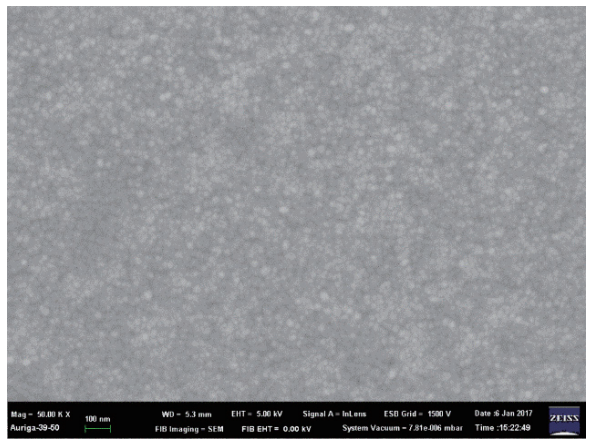

(b)

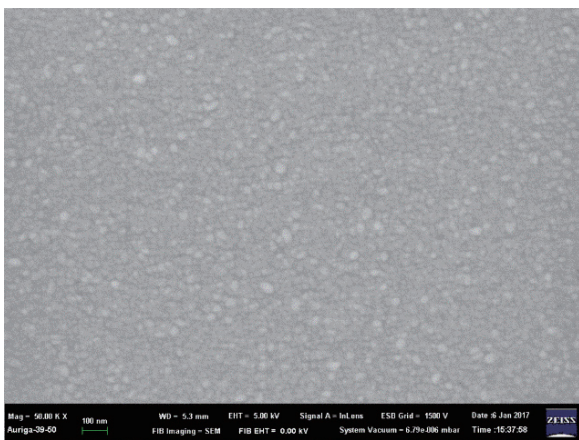

(d)

Fig. 5. (Color online) SEM surface features of FAZO films: (a) as-deposited, (b) annealed at $200{ }^{\circ} \mathrm{C}$, (c) annealed at $300{ }^{\circ} \mathrm{C}$, and (d) annealed at $400{ }^{\circ} \mathrm{C}$.

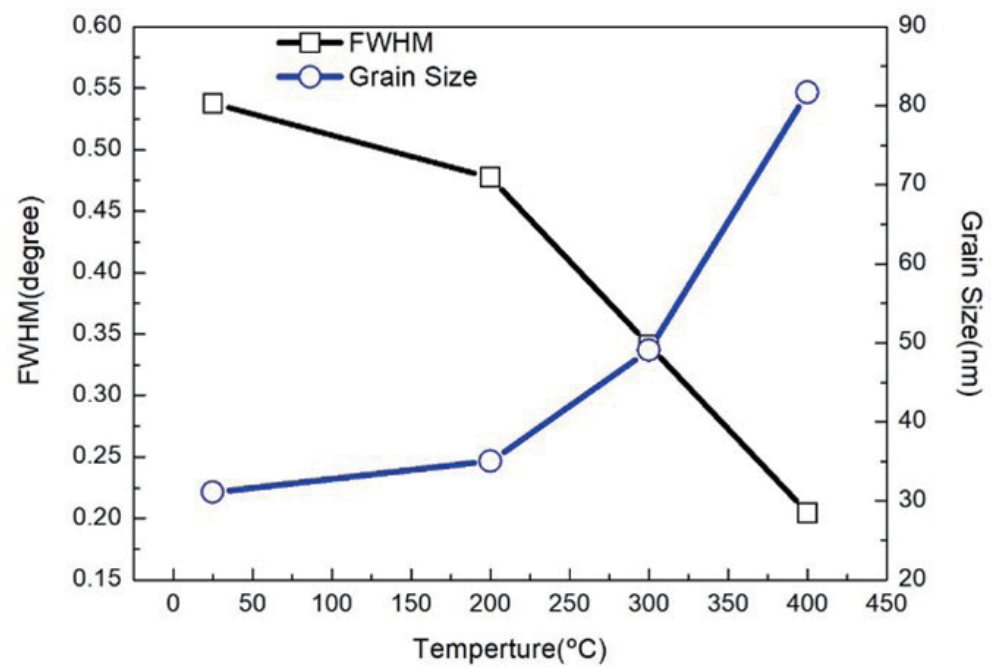

Fig. 6. (Color online) Grain size and FWHM of FAZO films annealed at different temperatures. 


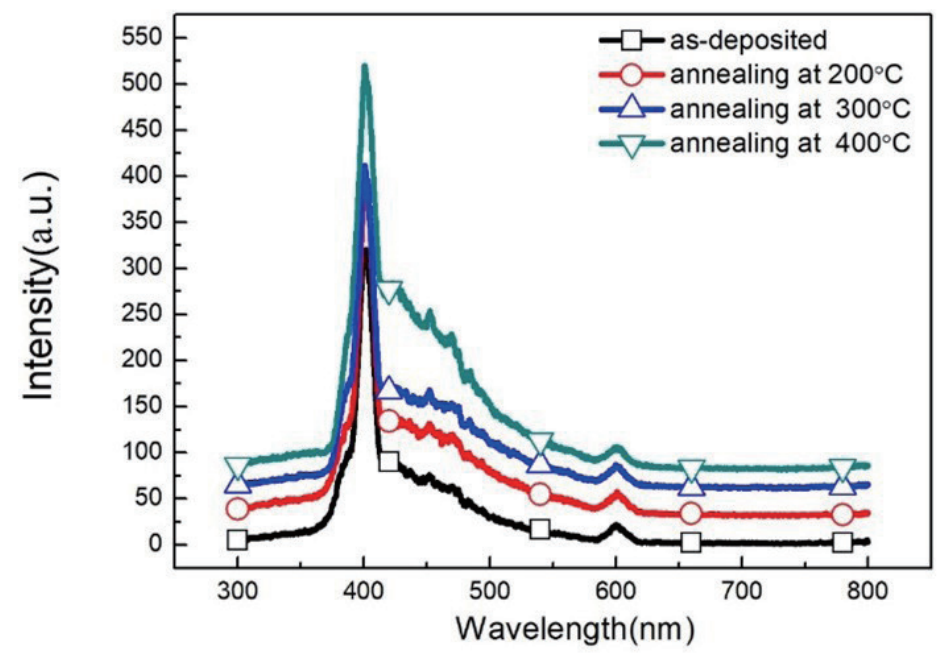

Fig. 7. (Color online) PL spectra of FAZO films annealed at different temperatures.

\subsection{PL spectroscopy}

$\mathrm{PL}$ is the spontaneous radiation that results from the linear excitation of photons. For $\mathrm{ZnO}$ thin films, emission bands are typically observed in the ultraviolet and visible regions of the PL spectrum. As shown in Fig. 7, the PL spectra of the present FAZO films are dominated by UV peaks with an intensity that increases with the annealing temperature. It is found that the crystal structure of the FAZO thin films increases with the annealing temperature owing to the increasing peak of PL spectra and that the optical and electrical properties of FAZO thin films also improve with increasing annealing temperature.

\section{Conclusion}

FAZO thin films were deposited on Corning glass substrates using an RF magnetron sputtering system. The electrical and optical properties of the as-deposited films and the films annealed at temperatures ranging from 200 to $400{ }^{\circ} \mathrm{C}$ were examined. XRD analysis results showed that the films have a typical wurtzite structure with a strong (002) preferential orientation. The electrical properties of the thin films improve with increasing annealing temperature owing to improved crystallization, a larger grain size, and a smaller surface roughness. The best electrical properties, namely, a resistivity of $4.1 \times 10^{-4} \Omega \cdot \mathrm{cm}$, a carrier concentration of $3.69 \times 10^{20} \mathrm{~cm}^{-3}$, and a Hall mobility of $65 \mathrm{~cm}^{2} / \mathrm{V} \cdot \mathrm{s}$, were obtained at an annealing temperature of $400{ }^{\circ} \mathrm{C}$. Moreover, the optical transmittance and energy bandgap also increased with the annealing temperature and had values of around $80 \%$ and $3.21 \mathrm{eV}$, respectively, at an annealing temperature of $400{ }^{\circ} \mathrm{C}$. Overall, the results presented in this study show that the FAZO film annealed at $400{ }^{\circ} \mathrm{C}$ has excellent potential for use in solar cells and photosensor applications. 


\section{Acknowledgments}

The authors would like to express their sincere gratitude to the Ministry of Science and Technology, Taiwan, for the financial support of this study under Grant Nos. MOST 106-2628-E-992-302-MY3 and 107-2221-E-992-060.

\section{References}

1 J. Jang, Y. Kang, D. Cha, J. Bae, and S. Lee: Crystal 9 (2019) 192

2 T. H. Chen, B. L. Jiang, and C. T. Huang: Smart Sci. 5 (2017) 53.

3 Z. Yan, J. Bao, X. Y. Yue, X. L. Li, Y. N. Zhou, and X. J. Wu: J. Alloy Compd. 812 (2019) 152093.

4 W. S. Liu, W. T. Hsieh, S. Y. Chen, and C. S. Huang: Sol. Energy 174 (2018) 83.

5 P. K. Shrestha, Y. T. Chun, and D. Chu: Light Sci. Appl. 4 (2015) e259.

6 S. L. Tu, T. H. Chen, Y. H. Su, and J. H. Yang: Opt. Quantum Electron. 48 (2016) 92.

7 Z. B. Zheng, J. T. Li, T. Ma, H. L. Fang, W. C. Ren, J. Chen, J. C. She, Y. Zhang, F. Liu, H. J. Chen, S. Z. Deng, and N.S. Xu: Light Sci. Appl. 6 (2017) el7057.

8 G. H. Jo, S. H. Kim, and J. H. Koh: Ceram. Int. 44 (2018) 735.

9 K. M. Sandeep, S. Bhat, and S. M. Dharmaprakash: J. Phys. Chem. Solids 104 (2017) 36.

10 T. H. Chen and C. L. Yang: Opt. Quant. Electron. 48 (2016) 533-1.

11 T. H. Chen and H. T. Su: Sens. Mater. 30 (2018) 2541.

12 W. L. Dang, Y. Q. Fu, J. K. Luo, A. J. Flewitt, and W. I. Milne: Superlattices Microstruct. 42 (2007) 89.

13 D. Yu, Y. Q. Yang, Z. Chen, Y. Tao, Y. F. Liu: Opt. Commun. 362 (2016) 43.

14 B. Y. Oh, M. C. Jeong, D. S. Kim, W. Lee, and J. M. Myoung: J. Cryst. Growth 281 (2005) 475.

15 C. F. Liu, T. H. Chen, and Y. S. Huang: Sens. Mater. 32 (2020) 2321.

16 S. Ishizuka, T. Yoshiyama, K. Mizukoshi, A. Yamada, and S. Niki: Sol. Energy Mater. Sol. Cells 94 (2010) 2052.

17 D. L. Zhu, Q. Wang, S. Han, P. J. Cao, W. J. Liu, F. Jia, Y. X. Zeng, X. C. Ma, and Y. M. Lu: Appl. Surf. Sci. 298 (2014) 208.

18 F. H. Wang and C .L. Chang: Appl. Surf. Sci. 370 (2016) 83.

19 B. L. Wen, M. Kumar, B. B. Sahu, S. B. Jin, C. Sawangrat, K. Leksakul, and J. G. Han: Surf. Coat. Technol. 284 (2015) 85.

20 A. Suzuki, T. Matsushita, T. Aoki, A. Mori, and M. Okuda: Thin Solid Films 411 (2002) 23.

21 T. Minami: Semicond. Sci. Technol. 20 (2005) S35.

22 Z. Pan, Y. Xiao, X. Tian, S. Wu, C. Chen, J. Deng, C. Xiao, G. Hu, and Z. Wei: Mater. Sci. Semicond. Process. 17 (2014)162.

23 S. Lemlikchia, S. Abdelli-Messaci, S. Lafane, T. Kerdja, A. Guittoum, and M. Saad: Appl. Sur. Sci. 256 (2010) 5650 .

24 B. G. Lewis and D. C. Paine: MRS Bull. 25 (2000) 22.

25 T. Y. Tsai, T. H. Chen, S. L. Tu, Y. H. Su, Y. H. Shen, and C. L. Yang: Opt. Quantum Electron. 48 (2016) 475.

26 T. H. Chen and T. Y. Chen: Nanomaterials 5 (2015) 1831.

27 R. Wendt, K. Ellmer, and K. Wiesemann: J. Appl. Phys. 82 (1997) 21152.

28 T. H. Chen and C. L. Yang: Opt. Quant. Electron. 48 (2016) 533.

29 S. J. Pearton, D. P. Norton, K. Ip, Y. W. Heo, and T. Steiner: Prog. Mater. Sci. 50 (2005) 293.

30 F. H. Wang, Y. H. Lee, T. H. Kang, and H. W. Liu: Superlattices Microstruct. 83 (2015) 289.

31 V. Assuncão, E. Fortunato, A. Marques, A. Goncalves, I. Ferreira, H. Aguas, and R. Martins: Thin Solid Films 442 (2003) 102.

32 J. Tauc: Mater. Res. Bull. 3 (1968) 37.

33 O. Stenzel: The Physics of Thin Film Optical Spectra: An Introduction (Springer International Publishing, Switzerland, 2005) 2nd ed., pp. 214.

34 Z. Pan, P. Zhang, X. Tian, G. Cheng, Y. Xie, H. Zhang, X. Zeng, C. Xiao, G. Hu, and Z. Wei: J. Alloy. Compd. 576 (2013) 31.

35 C. F. Liu, C. H. Kuo, T. H. Chen, and Y. S. Huang: Coatings 10 (2020) 394.

36 Z. Tseng, L. Chen, J. Tang, M. Shih, and S. Chu. J. Electron. Mater. 46 (2017) 1476.

37 Y. Liu and S. Zhu: Results in Physics 14 (2019) 102514.

38 E. Burstein: Phys. Rev. 93 (1954) 632.

39 K. G. Saw, N. M. Aznan, F. K. Yam, S. S. Ng, and S. Y. Pung: PLoS One 10 (2015) e0141180. 


\section{About the Authors}

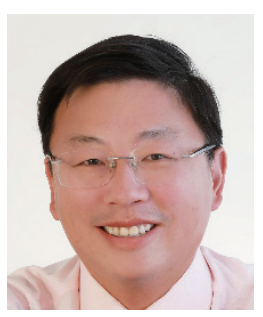

Chi-Fan Liu received his M.D. degree from the University of the Incarnate Word, U.S.A., in 2002. Since 2004, he has been an associate professor at Feng Chia University, Taiwan. Since 2019, he has been the head of Yuchi Township, Nantou County, Taiwan. Now, he is a Ph.D. graduate student at National Kaohsiung University of Science and Technology, Department of Mechanical Engineering, Kaohsiung, Taiwan. His research interests are in thin films, sport science, bioengineering, and sensors.

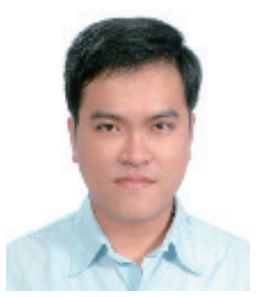

Tao-Hsing Chen received his B.S. degree from National Cheng Kung University, Taiwan, in 1999 and his M.S. and Ph.D. degrees from the Department of Mechanical Engineering, National Cheng Kung University, in 2001 and 2008, respectively. From August 2008 to July 2010, he was a postdoctoral researcher at the Center for Micro/Nano Science and Technology, National Cheng Kung University. In August 2010, he became an assistant professor at National Kaohsiung University of Applied Sciences (renamed National Kaohsiung University of Science and Technology), Taiwan. Since 2016, he has been a professor at National Kaohsiung University of Science and Technology. His research interests are in metal materials, TCO thin films, thermal sensors, and photosensors. (thchen@nkust.edu.tw)

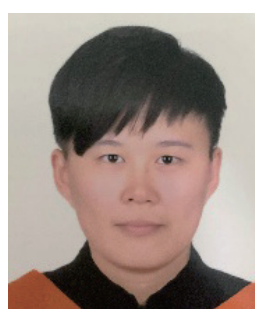

Jia-Ting Huang received her B.S. degree from I-Shou University, Taiwan, in 2015 and her M.S. degree from National Kaohsiung University of Science and Technology in 2017. She is now working at a semiconductor company. 